\title{
EUROPEANS STANDARDIZE DNA PROFILES
}

LONDON-In matters of life and death, of tragedy and grievance, and in the court proceedings that may follow, the quality of the evidence is of paramount importance. Consequently, under the glare of criticism of Lifecode's (Valhalla, NY) handling of the Castro murder case (Bio/Technology 8:505, June '90), a loose collection of European forensic laboratories formed the European DNA Profiling group (EDNAP) to develop standard procedures for DNA fingerprinting. According to EDNAP secretary and deputy director of the Metropolitan Police Laboratory (London) Peter Martin, the group wanted to forestall the criticism that had threatened the technique in the U.S. "We were determined to make sure that we set up our data systems appropriately and established suitable protocols."

In fact, EDNAP has gone beyond that by establishing standards to ensure the compatibility of data across the various participating laboratories. It has adopted $\operatorname{Hinf} \mathrm{I}$ as the restriction enzyme of choice (HaellI is the U.S. Federal Bureau of Investigation's standard) and all laboratories have agreed to use two key probes: Cellmark's (Abingdon, U.K.) MS43A and Promega's (Madison, WI) YNH24. Laboratories will turn to a variety of other probes in concluding particular cases, but the use of two stock types will let them cross-reference data.

An increasing number of European laboratories are tooling up to use the technique for forensic work. In Germany, the Bundes Kriminals Ampt (BKA, Federal Criminal Laboratory, Weisbaden) and three of the regional laboratories have casework in progress. In France, although no case has yet come to court, the Ministry of the Interior has given the green light to the technology and, following a blind trial of 18 prospective fingerprinting laboratories, has recently approved several; among them ICI Systems (Enghien-les-Bains), Appligene (Illkirch), and the hospital laboratories at Nantes and Rheim. State forensic laboratories in The Netherlands, Sweden, Norway, and Denmark are all active, with Denmark's first case just about to reach the courts. And Southern Europe is not far behind. In Italy, both the Carabineri and the scientific police are establishing laboratories. But in Spain, although both the forensic police laboratories and the Institute of Toxicology are interested in DNA profiling, concerns about radioactive probes have slowed its adoption. According to Paul Debenham, Cellmark's science director, the company will launch a line of nonradioactive probes in three to six months.

Cellmark has recently won the British Quality Standard 5750 award in recognition of its procedures for sample handling and documentation. These procedures, Debenham acknowledges, were "financially painful to set in motion," largely because they impose additional manpower requirements, and Debenham is trailing the idea that Cellmark could act as a reference centre to enable laboratories to compare their performance with others. Another option, howev$\mathrm{er}$, is for an independent organisation to become involved. Martin feels that the task may fall to the International Society for Forensic Haemogenetics (Aachen, F.R.G.), an organisation established to coordinate protocols for the collection of evidence in paternity cases. -John Hodgson

\section{HGS}

Invaluable in the estimation of Protein Structures

\section{Feature}

-Precision designed, light-weighted, flexible

-Bond angles variously \& precisely represented

-Firm bonding, shapes securely held -Free rotation, distortion

Un-assembled Models

- Student set

- Protein-Nucleic Acid model

- Protein Molecular model

- DNA, A-form, B-form, Z-form

-tRNA

Assembled Models

- Proteins and enzymes: lysozym (hen egg)

cytochrome c (tuna), others

- DNA, tRNA:

DNA-A, B, Z, tRNA Phe(yeast), others - Saccharides:

$\beta-(1,3)$-glucan, others

Welcome inquiries for: $=$

- New combinations

- Additions

- Modifications
HGS MOLECULAR STRUCTURE MODEL - Student kit

- Researcher models

- Crystal Structure Study

- Organic \& Inorganic

Chemistry

Assembled Models

- Superconductors: $\mathrm{Bi}_{2} \mathrm{Sr}_{2} \mathrm{CuO}_{6}$, others

-Zeolites: sodalite, others

HGS SPACE-FILLING

MOLECULAR MODEL

HGS STEREOCHEMISTRY MOLECULAR MODEL

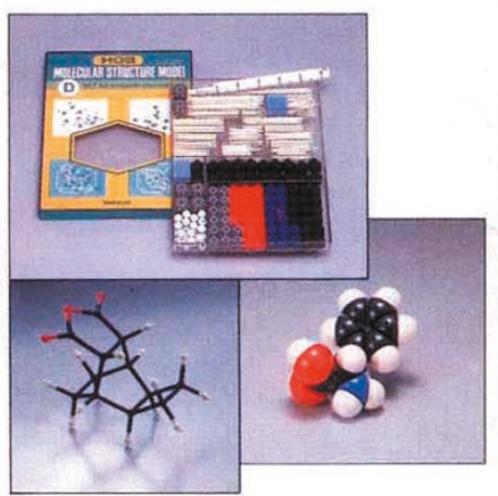

